\title{
Base on the Public Scientific Quality Improvement Research on Risk Early Warning of Online Shopping
}

\section{Xiaoyan Li}

Xi'an Technological University

Lixia Cao ( $\nabla$ caolx_8@163.com )

xi'an technologcal university https://orcid.org/0000-0001-6942-1565

\section{Tonghui Wang}

New Mexico State University

Xiangchu Feng

Xidian University

\section{Research Article}

Keywords: Public Scientific Quality, Risk Warning Method, Online Shopping, Complex Network

Posted Date: June 3rd, 2021

DOI: https://doi.org/10.21203/rs.3.rs-493778/v1

License: (c) (1) This work is licensed under a Creative Commons Attribution 4.0 International License. Read Full License 


\section{Abstract}

In order to improve the scientific quality of the public, the Chinese Association for Science and Technology has put forward a call to combine popular science education with leisure and entertainment. In view of the fact that online shopping involves a wide range of areas, and the people pay more attention to it, the paper completed the innovation of online shopping risk warning science knowledge, the design of popular science mechanism and the dissemination of popular science knowledge. The paper used complex network's knowledge discovery methods and decision theory to design online shopping risk warning science knowledge; Using the complex network public opinion dissemination trust analysis realize the dissemination of popular science knowledge and promote the improvement of the public's quality of popular science. The spread of risk early warning science knowledge in the network shows that the risk early warning mechanism designed can achieve the purpose of improving public science knowledge when the reward and punishment measures are appropriate.

\section{Full Text}

This preprint is available for download as a PDF.

\section{Figures}

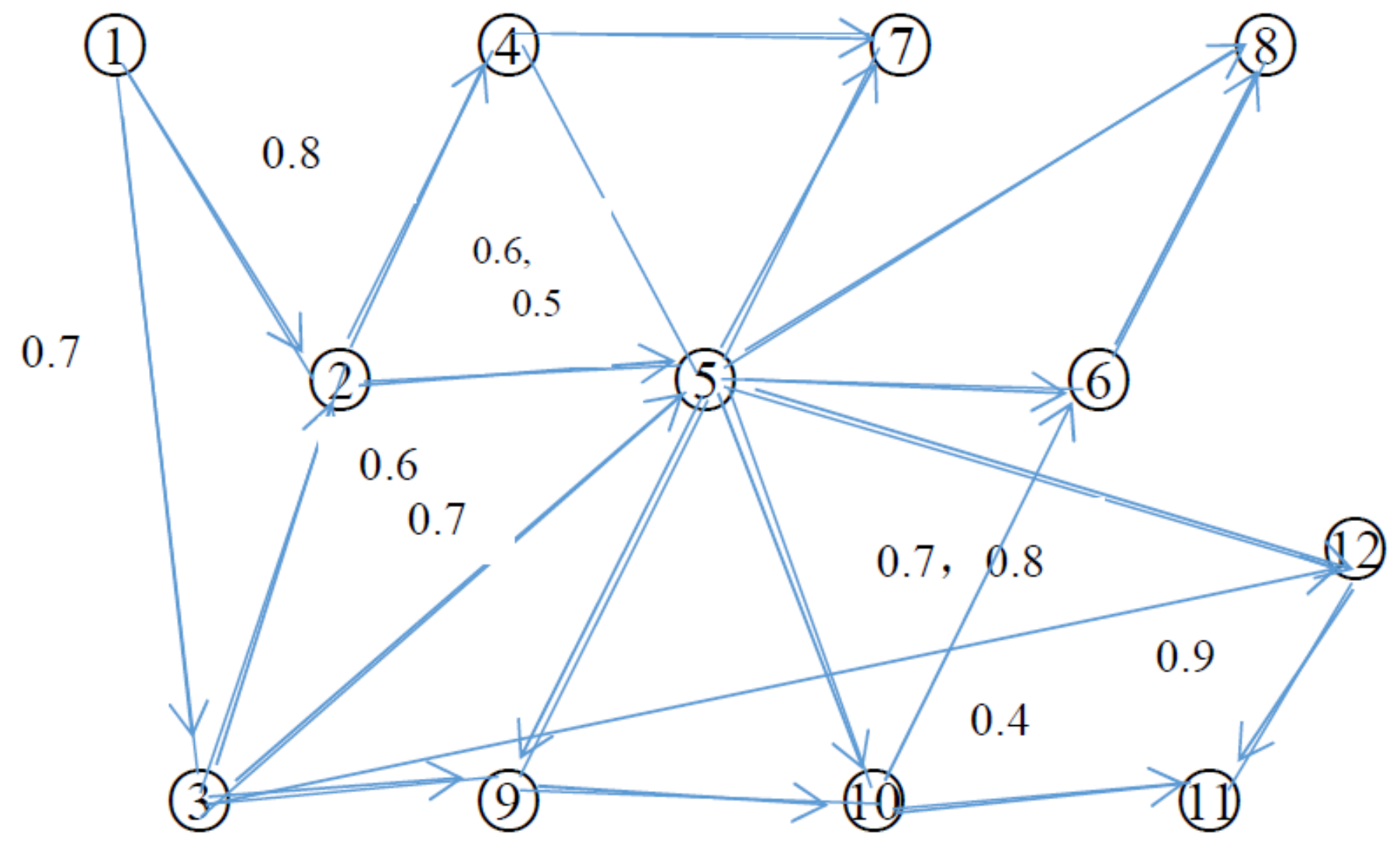

Figure 1 
The social network diagram of public opinion dissemination 